\title{
Urothelial Bladder Carcinoma in a Young Adult about an Unusual Case
}

Khdach Youness $^{1}$, Jamali Mounir ${ }^{1 *}$, Boukhlifi Youness ${ }^{1}$, Ameur Ahmed ${ }^{1}$, Alami Mohammed ${ }^{1}$

${ }^{1}$ Service of Urology, Military Hospital of Instruction Mohamed V, Hay Ryad - 10100 RABAT, Morocco

DOI: $10.36347 /$ sasjs.2021.v07i03.012

| Received: 05.03.2021 | Accepted: 23.03.2021 | Published: 30.03.2021

*Corresponding author: Jamali Mounir

\section{Abstract}

We report a case of urothelial bladder carcinoma at the military hospital in rabat, about a 32-year-old patient, chronic tobacco user. The symptoms were marked by the appearance of a macroscopic hematuria and dysuria. The ultrasound scan showed a left bladder wall tissue mass with pyelocalyceal upstream dilation. A biopsy was made during the transurethral resection of the bladder with a urothelial carcinoma on anatomopathological examination. The treatment consisted of a radical cystoprostatectomy with bilateral ilio-obturator lymphadenectomy before adjuvant chemotherapy. The evolution was marked by the death of the patient during chemotherapy.

Keywords: Bladder cancer, Urinary bladder, Urothelial carcinoma, Young adults.

Copyright (C) 2021 The Author(s): This is an open-access article distributed under the terms of the Creative Commons Attribution 4.0 International License (CC BY-NC 4.0) which permits unrestricted use, distribution, and reproduction in any medium for non-commercial use provided the original author and source are credited.

\section{INTRODUCTION}

Urothelial carcinoma of the bladder in young patients is rare, and less than $1 \%$ of such tumors present in the first 4 decades of life [1-4].

There is no unanimity on the clinical and evolutionary characteristics of these tumors. For some authors, these tumors are noninvasive low-grade tumors with low recurrence rate and, therefore, an improved prognosis. In contrast, some studies have observed similar patterns in younger and older patients [9].

The objective of this work was to report about the occurrence of a urothelial carcinoma occurrence in a 32-year-old youngster, and to discuss its clinical, pathological and therapeutic aspects.

\section{OBSERVATION}

O. J., 32 years old, single, a chronic smoker at a rate of 10 packs / year, without notable pathological history. He was admitted to the emergency room for macroscopic hematuria containing clots, associated with weight loss of $30 \mathrm{~kg}$ in 2 months. The clinical examination shows a thin patient weighing $50 \mathrm{~kg}$ with the presence of a distended bladder.

The rectal examination shows a firm and immobile low bladder fundus with a hard prostate estimated at $20 \mathrm{~g}$. Ultrasound shows a large left bladder diverticulum containing a tissue mass with pyelocalyceal upstream dilation.

A laboratory workup shows anemia at $10 \mathrm{~g} / \mathrm{dl}$ hemoglobin with normal renal function test. Biopsy was performed during the transurethral resection of the bladder due to the large size of the tumor and its infiltrating appearance with at least a high-grade urothelial carcinoma classified pT1, muscle not shown on anatomopathological examination. The thoracoabdomino-pelvic scanner shows a large diverticulum of the left bladder wall with a heterogeneous, largely necrotic tissue mass of $87 \times 66 \mathrm{~mm}$ with calcifications and invasion of the fat around the bladder associated with left and right external iliac nodes without visceral metastasis (Figure-1). 
Khdach Youness et al., SAS J Surg, Mar, 2021; 7(3): 158-162

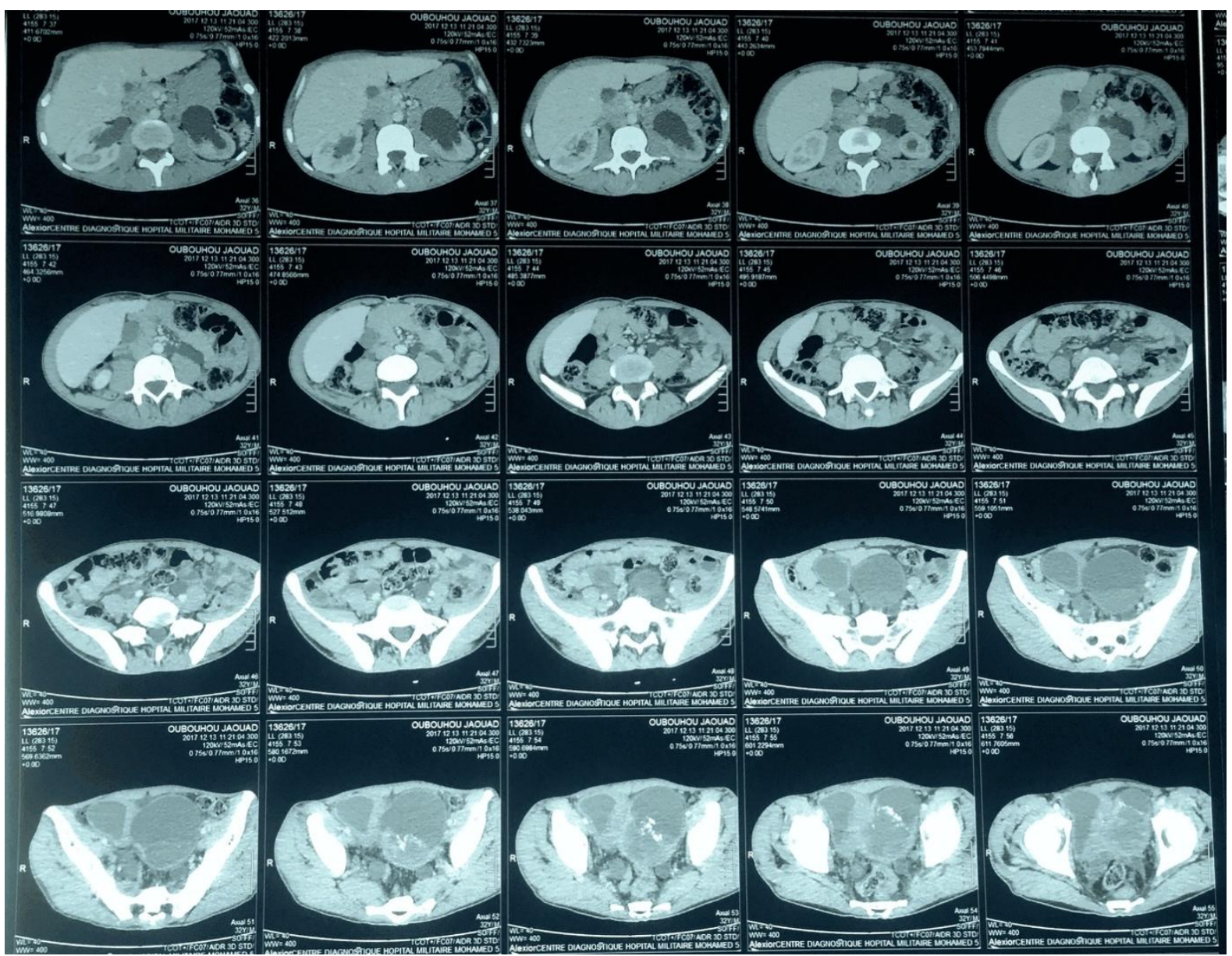

Fig-1: Pre operatory abdomino pelvic scan

Sperm cryopreservation was performed, before a radical hemostatic cystoprostatectomy which was performed urgently associated with bilateral ilio-obturator lymph nodes dissection and ligation of the right hypogastric after accidental sectioning of the latter given the technical difficulty and the tumor size (Figure $2 \& 3$ ).

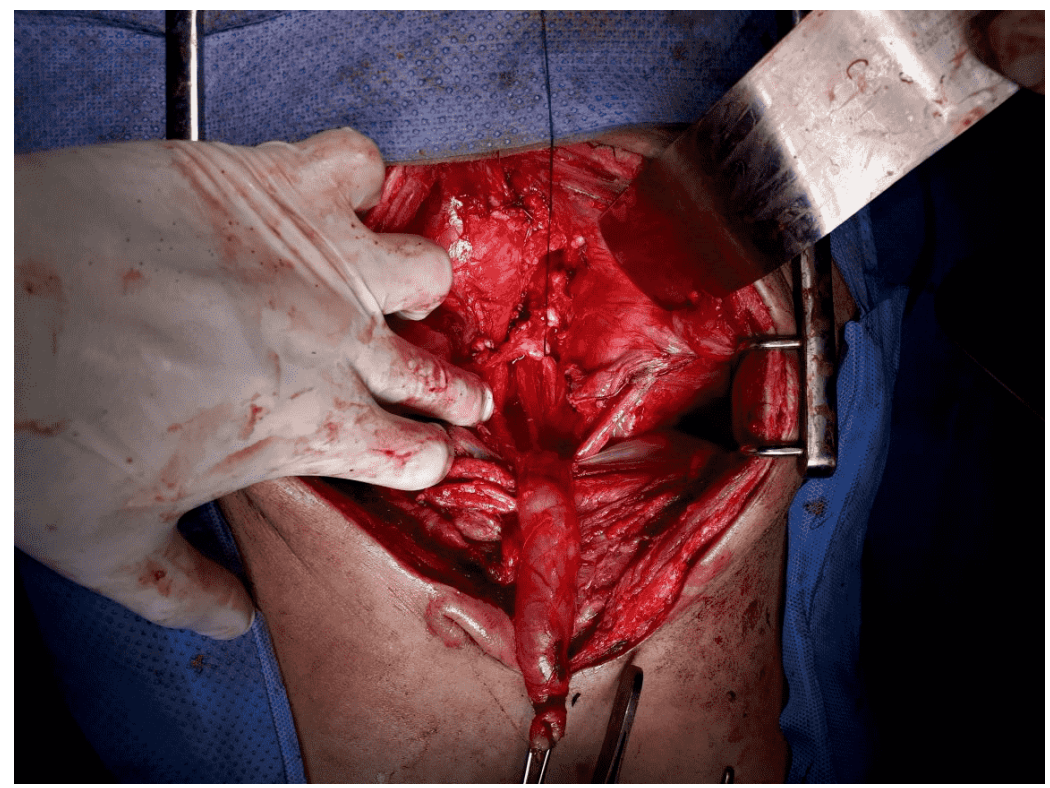

Fig-2: Per operative image 


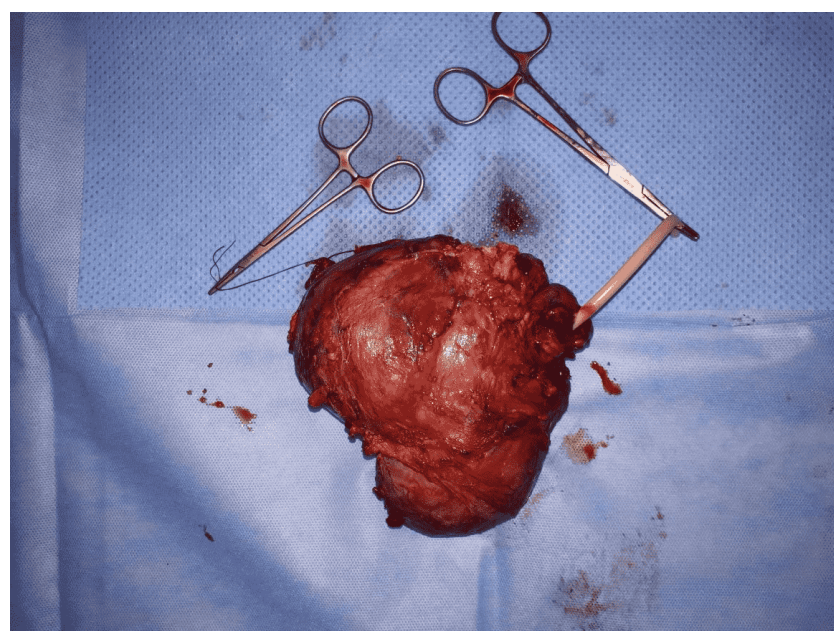

Fig-3: Operatory specimen

The anatomopathological examination of the operative specimen is in favor of a high grade urothelial carcinoma of the bladder infiltrating the prostate, the left seminal vesicle, but also the left ureteral and urethral sections infiltrated by the tumor, presence of peritumoral vascular emboli and perinervous sheath, with 6 out of 15 left lymph nodes affected with capsular rupture and 11 out of 12 right nodes affected with capsular rupture: stage pT4a N2 R1 Mx.

The patient presented a subocclusive syndrome with cessation of stools and gas and underwent an abdominopelvic scan which did not show any noticeable abnormality (Figure-4).

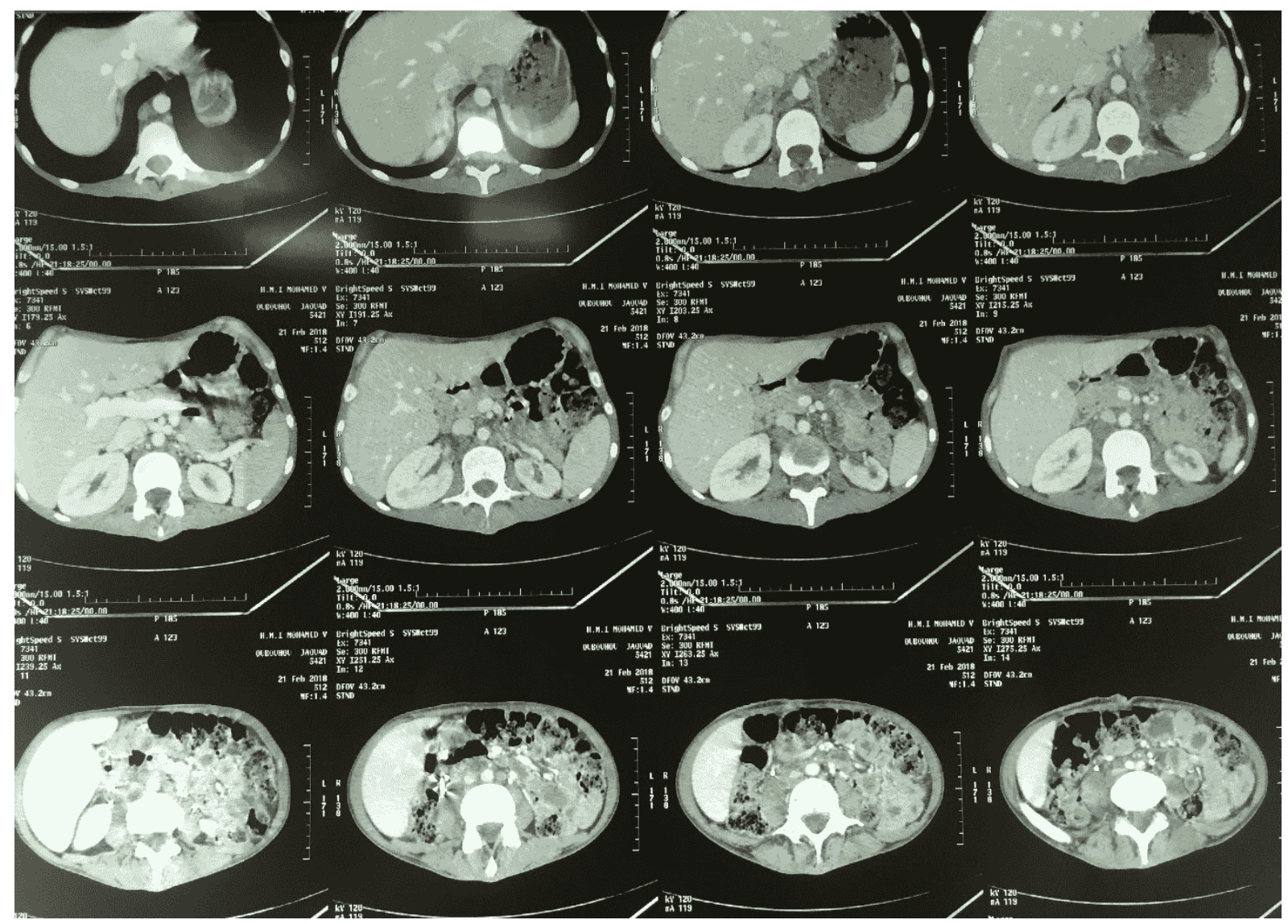

Fig-4: Post operatory abdomino pelvic scan

The postoperative course was simple with normal renal function. The patient was sent to oncology for adjuvant chemotherapy. Unfortunately the patient died after the first cycle of Cysplatin.

\section{DISCUSSION}

Bladder tumors are diagnosed in 2.7 million people worldwide each year and typically appear after age $60[10,11]$. These tumors can nevertheless concern 
the young subject of less than 40 years in 0.4 to $1 \%$ of cases [1-4].

The majority of bladder tumors are revealed by hematuria, often terminal, which is the most common clinical sign. Signs of bladder irritation (pollakiuria, Urinary urgency, urinary burn), in the absence of urinary tract infection, are observed in 4 to $20 \%$ of cases [12, 13]. For our patient, clotting macroscopic hematuria associated with dysuria were the telltale symptoms. The weight loss raised suspicion of a malignant tumor process.

The risk factor found in the patient is smoking, which remains preponderant among the risk factors for bladder tumor in the elderly as in the young subject. This risk is classically linked to the number of packages / year and the degree of inhalation of the smoke [5]. We also find occupational exposure to solvents and chemicals or schistosomiasis.

Sedentary lifestyle and metabolic syndrome have also been correlated with an increased risk of VT $[14,15]$.

In a review of the literature, Kutarski demonstrated the clear predominance of superficial tumors, and especially Ta stages, and was interested in the variation in histological stage as a function of age. Thus, if the Ta tumor rate is $77 \%$ during the 4 th decade, before age 20 , this rate reaches $95 \%[17,5]$.

Regarding infiltrating tumors, the results are again very variable depending on the series. For Blanchard [5], who collected data from several series, including Javadpour [2], Kutarski [17] and Aboutaieb [16], it was possible to isolate 69 infiltrating tumors out of a total of 539 staged tumors, therefore a rate of $13 \%$. Of these 69 infiltrating tumors, $61 \%$ exceeded the limits of the bladder (stage> T3). The histology of our patient revealed urothelial carcinoma infiltrating adjacent structures stage pT4. Usually, urothelial tumors tend to be superficial and Ta stage, well differentiated and unifocal. Conversely, infiltrating urothelial tumors are most often very aggressive [6-8].

There seems to be a more favorable prognosis in superficial bladder tumors developed before age 30 and particularly before age 20. Conversely, infiltrating tumors in this population seem very aggressive and therefore have a very poor prognosis. Between 30 and 40 years, the evolution of superficial and infiltrating killers is comparable to the older subject [5].

Patients with initial lymph node involvement on the extension workup are more sensitive to chemotherapy. A multimodal approach can be offered to them, with a first chemotherapy. For patients with a complete radiological response, a cystectomy may be performed. Patients with a complete histological response to glandular dissection have an estimated survival of $66 \%$ at 5 years. The remaining patients have a prognosis similar to metastatic patients and should therefore be considered as such for treatment and follow-up. For patients classified as T4 at the time of the extension workup, with a tumor deemed to be nonextirpable according to the usual surgical procedures, induction chemotherapy is also recommended [18].

\section{CONCLUSION}

Bladder tumors in young people are quite rare; the delay between the onset of symptoms and the diagnosis poses the problem of screening because of the non-suspicion of a tumor cause in the young subject.

The prognosis seems more favorable for bladder tumors developed before 30 years old, with few recurrences. After 30 years, the risk is comparable to that of the elderly.

\section{REFERENCES}

1. Cherrie RJ, Lindner A, Dekernion JB. Transitional cell carcinoma of bladder in first four decades of life. Urology. 1982; 20: 582-584.

2. Javadpour N, Mostofi FK. Primary epithelial tumors of the bladder in the first two decades of life. J Urol. 1969; 101:706-710.

3. Johnson DE, Hillis S. Carcinoma of the bladder in patients less than 40 years old. J Urol. 1978; 120: 172-173.

4. Mccarthy JP, Gavrell GJ, Leblanc GA. Transitional cell carcinoma of bladder patients under thirty years of age. Urology. 1979; 13: 487489.

5. Blanchard JM, Graziana JP, Bonnal JL, Biserte J, Mauroy B. tumeurs de vessie du sujet jeune : à propos de 26 cas.comparaison aux données de la littérature, Prog Urol. 2003; 13, 227-233.

6. Greene LF, Hanas KA, Farrow OM. Benign papilloma or papillary carcinoma of the bladder? J Urol. 1973; 110: 205-207.

7. Lerman RI, Nutter RV, Withemore. Papilloma of the urinary bladder. Cancer. 1970; 25: 333-342.

8. Prout GR, Bassil B, Griffin P. The treated histories of patients with TaG1 transitionnal cell carcinoma of bladder. Arch Surg. 1986;121:1463-1468.

9. Yossepowitch O, Dalbagni G. Transitional cell carcinoma of the bladder in young adults: presentation, natural history and outcome. J Urol, 2002; 168, pp. 61-66.

10. Siegel RL, Miller KD, Jemal A. Cancer statistics, 2016. CA Cancer J Clin. 2016;66:7-30.

11. Uhry Z, Remontet L, Colonna M, Belot A, Grosclaude P, Mitton N. Cancer incidence estimation at a district level without a national registry: a validation study for 24 cancer sites using French health insurance and registry data. Cancer Epidemiol. 2013;37:99-114.

12. Pfister C, Roupret M, Neuzillet Y, Larre S, Pignot G, Quintens H. Recommandations en onco- 
urologie 2013 du CCAFU: Tumeurs de la vessie. Prog Urol. 2013;23:S105-25.

13. Dobbs RW, Hugar LA, Revenig LM, Al-Qassab S, Petros JA, Ritenour CW. Incidence and clinical characteristics of lower urinary tract symptoms as a presenting symptom for patients with newly diagnosed bladder cancer. Int Braz $\mathbf{J}$ Urol 2014;40:198-203.

14. Keimling M, Behrens G, Schmid D, Jochem C, Leitzmann MF. The association between physical activity and bladder cancer: systematic review and meta-analysis. Br J Cancer. 2014;110:1862-70.

15. Montella M, Di Maso M, Crispo A, Grimaldi M, Bosetti C, Turati F. Metabolic syndrome and the risk of urothelial carcinoma of the bladder: a casecontrol study. BMC Cancer. 2015;15:720.

16. Aboutaieb R, Dakir M, Sarrf I. Les Tumeurs de vessie chez le sujet jeune. Prog Urol. 1998; 8: 4346.

17. Kutarski PW, Padwell A. Transitional cell carcinoma of the bladder in young adults. $\mathrm{Br} \mathrm{J}$ Urol. 1993; 72: 749-755.

18. Rouprêt M, Neuzillet Y, Pignot G, Compérat E, Audenet F, Houédé N, Larré S, Masson-Lecomte A, Colin P, Brunelle S, Xylinas E, Roumiguié M, Méjean A. Recommandations françaises du comité de cancérologie de l'AFU - actualisation 20182020: tumeurs de la vessie. Prog Urol, 2018, 28, R48, suppl. S1. 